\title{
Statin Therapy and Serum Testosterone in Men with Type 2 Diabetes
}

\author{
Mohammed Fakhraldeen*, Huseen Saad Mostafa** \\ *Faculty of medicine, Mansoura University \\ **King Fahd hospital, Riyadh, Saudi Arabia
}

\begin{abstract}
OBJECTIVE

There is a high prevalence of hypogonadism in men with type 2 diabetes. Statins could potentially decrease testosterone levels by reducing the availability of cholesterol for androgen synthesis. In this study we compared testosterone levels and hypogonadal symptoms with statin use in men with type 2 diabetes.
\end{abstract}

\section{PATIENTS AND METHODS}

Total testosterone, sex hormone-binding globulin (SHBG), and estradiol were measured by an enzyme-linked immunosorbent assay. Bioavailable testosterone was measured by the modified ammonium sulfate precipitation method. Free testosterone was calculated using Vermeulen's formula. Symptoms of hypogonadism were assessed using the Androgen Deficiency in the Aging Male questionnaire.

\section{RESULTS}

Statins were associated with lower total testosterone and a trend toward lower SHBG compared with untreated patients. Bioavailable testosterone, free testosterone, estradiol, and hypogonadal symptoms were not affected. Atorvastatin was associated with reduced total testosterone and a trend toward reduced SHBG compared with no treatment, and there was a dose-response effect with the lowest levels of total testosterone seen in men treated with $\geq 20 \mathrm{mg}$ atorvastatin .Simvastatin use was not associated with significant reductions in testosterone or SHBG levels.

\section{CONCLUSION}

Assessing androgen status using total testosterone in men with type 2 diabetes treated with statins, particularly atorvastatin, may potentially lead to diagnostic error. Levels of bioavailable testosterone or free testosterone are recommended for the assessment of hypogonadism in this group if total testosterone levels are borderline.

Key words: Type 2 DM, testosterone, hypogonadism, statin therapy.

\section{Introduction}

There is evidence that men with the metabolic syndrome, type 2 diabetes, and cardiovascular disease have a high prevalence of low circulating levels of testosterone (Jones TH, 2007). A significant proportion of these men are hypogonadal, defined as a combination of clinical symptoms and biochemical evidence of testosterone deficiency (Kapoor et al, 2007). Studies have shown that about $20 \%$ of men with metabolic syndrome, diabetes, and cardiovascular disease have testosterone levels below the normal range, and there are a further $20-25 \%$ with levels in the low normal range that may also be compatible with a diagnosis of 
hypogonadism, depending on clinical symptoms (Kapoor et al, 2007).

The great majority of men with diabetes and cardiovascular disease are being treated with statins. Cholesterol is the substrate for testosterone biosynthesis, and theoretically, hydroxymethylglutaryl-CoA reductase inhibitors such as statins could affect serum testosterone levels. Animal studies have shown that statins can reduce testosterone production when given in high doses (MacDonald et al, 1988). Studies in humans have shown various results. The majority have shown no effect of statins on testosterone levels (Santini et al, 2006), but some have shown reduced testosterone levels with simvastatin treatment (Dobs et al, 2000).

Total testosterone is the most widely used biochemical test in the diagnosis of men with hypogonadism. Total testosterone comprises free testosterone $(2-3 \%)$ and testosterone bound to either sex hormonebinding globulin (SHBG) $(60-80 \%)$ or albumin (20-40\%) (Behre et al, 2004). Free plus albumin-bound testosterone is generally regarded as the biologically active or bioavailable component. Testosterone bound to SHBG is considered to be inactive although recent research has suggested that SHBG-bound testosterone may be taken into cells by endocytosis, possibly allowing biological actions (Lorentozon et al, 2005). Studies have demonstrated that bioavailable or free testosterone better reflects androgen status, for example, by correlations with bone mineral density and erectile dysfunction (Morris et al, 2004).

In this study we analyzed the effect of statins on testosterone levels in men with type 2 diabetes.

\section{Patients and Methods}

250 men were Included in this study, aged $>40$ years, with type 2 diabetes under chronic follow up and management in the diabetes care outpatient clinic, King Fahd hospital, Riyadh, Saudi Arabia.

Medical history and drug histories were collected using a questionnaire.

Other measurements were taken included blood pressure, A1C, lipids, height, weight, and waist circumference.

Symptoms of hypogonadism were assessed by completion of the Androgen Deficiency in the Aging Male (ADAM) questionnaire, which was validated to assess hypogonadism in aging men (Morley et al, 2000).

1. Do you have a decrease in libido (sex drive)?

2. Do you have a lack of energy?

3. Do you have a decrease in strength and/or endurance?

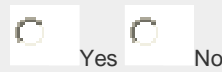

4. Have you lost height?

5. Have you noticed a decreased "enjoyment of life"

6. Are you sad and/or grumpy?

7. Are your erections less strong?
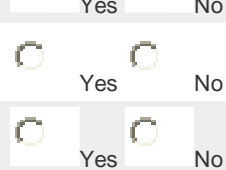

8. Have you noticed a recent deterioration in your ability to play sports?

9. Are you falling asleep after dinner?
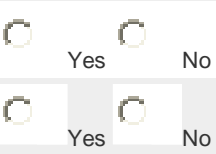

10. Has there been a recent deterioration in your work performance?
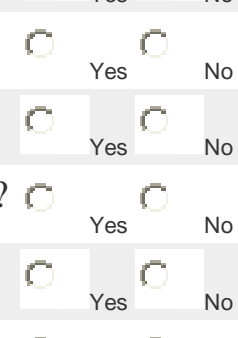
Serum total testosterone, total estradiol, and SHBG were measured by an enzyme-linked immunosorbent assay. (Grainne et al 2007). Bioavailable testosterone was determined by a modification of the ammonium sulfate precipitation method. (Tremblay et al, 1974).

Free testosterone was calculated from total testosterone and SHBG by the formula of Vermeulen et al (1971).

Statistical analysis was done using the Student's $\mathbf{t}$ test, the single-sample Kolmogorov-Smirnov test and the twosample Kolmogorov-Smirnov test.
Statistical significance was defined as $\mathbf{P}<$ 0.01 .

\section{Results}

In 250 men with type 2 diabetes, 105 were not treated with statins. Of 145 men treated with statins, 75 were treated with atorvastatin, 55 with simvastatin, 7 with pravastatin, 5 with fluvastatin and 3 with cerivastatin.

Patients treated with statins did not significantly differ from untreated individuals in age, waist circumference, BMI, A1C, or blood pressure.

Table 1

Mean sex hormone levels, measures of obesity, and cholesterol levels in men treated with atorvastatin, and simvastatin compared with untreated men

\begin{tabular}{llllll}
$\begin{array}{l}\text { No } \\
\text { statin }\end{array}$ & Statin & & Atorvastatin & \multicolumn{2}{c}{ Simvastatin } \\
105 & 145 & P value & 75 & P value & P value
\end{tabular}

\begin{tabular}{|c|c|c|c|c|c|c|c|}
\hline $\begin{array}{l}\text { Total testosterone } \\
(\mathrm{nmol} / \mathrm{l})\end{array}$ & 14.3 & 11.7 & 0.006 & 11.4 & 0.006 & 12.46 & 0.13 \\
\hline $\begin{array}{l}\text { Bioavailable } \\
\text { testosterone } \\
(\mathrm{nmol} / \mathrm{l})\end{array}$ & 4.16 & 3.89 & 0.133 & 3.83 & 0.151 & 3.95 & 0.292 \\
\hline $\begin{array}{l}\text { Free testosterone } \\
(\mathrm{nmol} / \mathrm{l})\end{array}$ & 0.286 & 0.264 & 0.228 & 0.258 & 0.308 & 0.265 & 0.125 \\
\hline SHBG (nmol/l) & 36.3 & 29.5 & 0.034 & 27.8 & 0.022 & 32.8 & 0.392 \\
\hline Estradiol (pmol/l) & 24.2 & 24.0 & 0.763 & 24.6 & 0.193 & 24.3 & 0.705 \\
\hline $\begin{array}{l}\text { Waist } \\
\text { circumference } \\
(\mathrm{cm})\end{array}$ & 109.7 & 109.9 & 0.919 & 110.9 & 0.26 & 109.3 & 0.513 \\
\hline $\mathrm{BMI}\left(\mathrm{kg} / \mathrm{m}^{2}\right)$ & 32.18 & 32.46 & 0.646 & 33.51 & 0.108 & 32.25 & 0.252 \\
\hline $\begin{array}{l}\text { Total cholesterol } \\
(\mathrm{mmol} / \mathrm{l})\end{array}$ & 5.06 & 4.57 & $<0.01$ & 4.63 & 0.01 & 4.51 & $<0.01$ \\
\hline ADAM score & 4.14 & 4.25 & 0.26 & 4.07 & 0.809 & 4.2 & 0.675 \\
\hline
\end{tabular}

1-Total testosterone was significantly lower in the statin and atorvastatin groups but not in the simvastatin group.

2-Bioavailable and free testosterone levels were not significantly different in all groups.

3-Both statins were associated with lower cholesterol levels than the untreated group, but were not significantly different between simvastatin and atorvastatin-treated groups 
4-No significant differences regarding BMI, waist circumference and ADAM score between the all groups

Table 2

Average testosterone, SHBG, and measures of obesity in men treated with atorvastatin split into two groups: those treated with $10 \mathrm{mg}$ and those treated with $20 \mathrm{mg}$ or more

\begin{tabular}{lllllll} 
& \multicolumn{5}{c}{ Atorvastatin } \\
& No statin & & \\
N & 105 & 45 & P & value $\geq 20 \mathrm{mg}$ & P value \\
Total testosterone (nmol/l) & 14.3 & $\mathbf{1 0 . 8}$ & $\mathbf{0 . 0 0 3}$ & $\mathbf{9 . 6 2}$ & $\mathbf{0 . 0 0 3}$ \\
Bioavailable testosterone (nmol/l) & 4.16 & 3.7 & 0.197 & 3.71 & 0.598 \\
Free testosterone (nmol/l) & 0.286 & 0.258 & 0.129 & 0.248 & 0.538 \\
SHBG (nmol/l) & 36.3 & 30.2 & 0.322 & 28.6 & 0.043 \\
Waist circumference $(\mathrm{cm})$ & 109.7 & 112.4 & 0.5 & 114 & 0.829 \\
BMI $\left(\mathrm{kg} / \mathrm{m}^{2}\right)$ & 32.18 & 33.25 & 0.348 & 34.88 & 0.0 .755 \\
Total cholesterol $(\mathrm{mmol} / \mathrm{l})$ & 5.06 & $\mathbf{4 . 5 4}$ & $\mathbf{0 . 0 0 3}$ & $\mathbf{4 . 5 2}$ & $\mathbf{0 . 0 0 3}$
\end{tabular}

1-There is a significant difference in total testosterone between untreated and atorvastatintreated patients with tendency to lower levels with higher doses.

2- There is a trend toward lower bioavailable testosterone, free testosterone and SHBG levels in men taking atorvastatin, but this does not reach statistical significance.

\section{Discussion}

In this study we found that patients treated with atorvastatin had lower levels of total testosterone with a trend toward lower SHBG compared with untreated men, whereas those treated with simvastatin were not significantly affected. The effects were particularly evident in those men taking higher doses of atorvastatin. Statin treatment did not significantly affect the biologically active fractions of testosterone, symptoms of hypogonadism, or estradiol levels.The study demonstrated that treatment with statins in patients with type 2 diabetes can be a confounding factor in the assessment of hypogonadism. Total testosterone is the primary test used in the diagnosis of hypogonadism, and the effect of atorvastatin could potentially lead to misdiagnosis of hypogonadism in men with normal free and bioavailable testosterone levels. The ADAM questionnaire failed to detect an increase in hypogonadal symptoms in groups with lower total testosterone levels and the questionnaire does not correlate closely with testosterone levels.
Other studies about testosterone levels in statin-treated patients showed various results:

1-Testosterone levels are frequently reduced in men with type 2 diabetes treated with statins (Ding et al, 2006).

2-In statin-treated men it has been confirmed that reductions in total testosterone are accompanied by similar changes in free and bioavailable testosterone and a high prevalence of hypogonadal symptoms, however men with diabetes may have a high level of falsepositive hypogonadal symptoms such as erectile dysfunction owing to vascular and neuropathic factors, medications, and depression (Kapoor et al, 2007).

3- One clinical trial studied the effects of atorvastatin on testosterone levels in men, the results showed a nonsignificant fall in total testosterone and no change in SHBG (Santini et al, 2006).

4-There are more published data concerning the effects of simvastatin on testosterone. Some trials have shown that simvastatin 
reduces serum testosterone levels (Dobs et al, 2000), whereas others have shown no effect (Azzarito et al, 1992). Results in our study suggest that any effect of simvastatin in reducing serum testosterone levels is not clinically significant in men with type 2 diabetes.

Studies in hypogonadal diabetic men have shown improvements in glycemic control, central obesity, and serum leptin during testosterone replacement therapy (Kapoor et al, 2006). Other studies have shown beneficial effects on further cardiovascular risk factors including total cholesterol levels (Malkin et al, 2004). In this context, it is important to assess for hypogonadism in men with type 2 diabetes. However, the assessment of the clinical syndrome of hypogonadism can be challenging in this group because of the confounding effects of vascular disease, psychological factors, and medications on symptoms such as erectile dysfunction. It is therefore especially important to adequately assess biochemical testosterone status. This assessment is complicated by low SHBG levels, which have long been associated with insulin resistance, leading to suggestions that low testosterone levels in type 2 diabetes are due to low SHBG rather than to reductions in bioactive testosterone fractions. This suggestion has been refuted by studies showing low free and bioavailable testosterone levels in men with type 2 diabetes (Hyyppa et al, 2003) and metaanalysis data suggesting relatively small changes in SHBG in men with diabetes (Ding et al, 2006).

The possible reduction of testosterone in statin-treated patients can be explained by the following:

1-In a normal physiological state, luteinizing hormone $(\mathrm{LH})$ promotes uptake of cholesterol by the testis and stimulates testosterone synthesis. A reduction in testosterone is sensed by the hypothalamicpituitary axis and leads to greater $\mathrm{LH}$ release, which completes a feedback loop and maintains testosterone levels. The apparent failure of the hypothalamicpituitary-testicular axis to respond and maintain testosterone levels in the statintreated patients may be explained by the hypogonadal-obesity-adipocytokine hypothesis (Jones TH, 2007). The majority of the patients in our study were overweight or obese. In this population, greater production of adipocytokines such as tumor necrosis factor- $\alpha$, interleukin- 6 , and leptin and increased estradiol from metabolism of testosterone by aromatase in adipose tissue inhibit LH release from the pituitary gland, which leads to lower circulating testosterone levels. Resistin is another adipocytokine that is produced by the adipose tissue and may be involved in the pathogenesis of low testosterone level in obese diabetic patients and it was stated that Resistin may act as the link between androgen and insulin resistance (Gonzalez et al,2008).

2-An alternative hypothesis is that atorvastatin causes a primary reduction in SHBG with consequent reductions in total testosterone. In our study there was a consistent trend toward low SHBG levels in all groups with reduced levels of total testosterone, although these low levels did not reach statistical significance. SHBG is produced in the liver, the primary site of action of the statins, but the mechanism by which statins could alter SHBG is unknown. SHBG levels are known to be modulated by a number of factors including downregulation by insulin resistance and upregulation by estrogens (Hampl et al, 1996).

International guidelines have suggested that symptomatic men with total testosterone levels $<8 \mathrm{nmol} / \mathrm{l}$ are hypogonadal, that men with total testosterone levels $>12 \mathrm{nmol} / \mathrm{l}$ do not have hypogonadism, and that men with levels between 8 and $12 \mathrm{nmol} / \mathrm{l}$ need consideration for treatment depending on their clinical picture. The Endocrine Society Clinical Practice Guideline suggested a diagnostic cutoff value of testosterone of $<10.4 \mathrm{nmol} / \mathrm{l}$ for hypogonadism (Nieschlag et al, 2005).

\section{Conclusion}

There is a significant effect of statins in lowering total testosterone and SHBG levels in men with type 2 diabetes. Assessing androgen status using total 
testosterone in men with type 2 diabetes treated with statins, particularly atorvastatin, may potentially lead to diagnostic error. Levels of bioavailable testosterone or free testosterone are recommended for the assessment of hypogonadism in this group if total testosterone levels are borderline.

\section{Reference}

- Azzarito C, Boiardi L, Zini M, Agosti A, Dotti C, Biagi R,Portioli I (1992). Long-term therapy with high-dose simvastatin does not affect adrenocortical and gonadal hormones in hypercholesterolemic patients. Metabolism 41: $148-153$

- Behre HM ,Rommerts FFG (2004)

Testosterone: an overview of biosynthesis, transport, metabolism and non-genomic actions. In Testosterone. Action, Deficiency, Substitution. Behre HM: Ed. Cambridge, Cambridge University Press, 1- 38

- Ding EL, Song Y, Malik VS, Liu S (2006). Sex differences of endogenous sex hormones and risk of type 2 diabetes: a systematic review and meta-analysis. JAMA 295: 1288- 1299

- Dobs AS, Miller S, Neri G, Weiss S, Tate AC, Shapiro DR,Musliner TA (2000). Effects of simvastatin and pravastatin on gonadal function in male hypercholesterolemic patients. Metabolism 49: 115- 121

- Hampl R, Starka L (1996). Sex hormonebinding globulin in endocrine regulation (minireview). Endocr Regul 30: 57- 65

- Hyyppa MT, Kronholm E, Virtanen A, Leino A, Jula A (2003). Does simvastatin affect mood and steroid hormone levels in hypercholesterolemic men? A randomized double-blind trial. Psychoneuroendocrinology 28: $181-194$

- Jones TH (2007). Testosterone associations with erectile dysfunction, diabetes and the metabolic syndrome. Eur Urol Suppl 6: 847857

- Kapoor D, Aldred H, Clark S,Channer KS, Jones TH (2007). Clinical and biochemical assessment of hypogonadism in men with type 2 diabetes: correlations with bioavailable testosterone and visceral adiposity. Diabetes Care 30: 911-917

- Kapoor D, Goodwin E, Channer KS,Jones TH (2006). Testosterone replacement therapy improves insulin resistance, glycaemic control, visceral adiposity and hypercholesterolaemia in hypogonadal men with type 2 diabetes. Eur

J Endocrinol 154: 899-906

- Lorentzon M, Swanson C, Andersson N, Mellstrom D, Ohlsson C (2005). Free testosterone is a positive, whereas free estradiol is a negative, predictor of cortical bone size in young Swedish men: the GOOD study. J Bone Miner Res 20: 1334- 1341

- MacDonald JS,Gerson RJ,Kornbrust DJ,Kloss MW, Prahalada S, Berry PH, Alberts AW, Bokelman DL (1988). Preclinical evaluation of lovastatin. Am J Cardiol 62: 16J27J

- Malkin CJ, Pugh PJ, Jones RD, Kapoor D, Channer KS,Jones TH (2004). The effect of testosterone replacement on endogenous inflammatory cytokines and lipid profiles in hypogonadal men. J Clin Endocrinol Metab 89: 3313-3318

- Morley JE, Charlton E, Patrick P, Kaiser FE, Cadeau P,McCready D, Perry HM (2000). Validation of a screening questionnaire for androgen deficiency in aging males.

Metabolism 49: 1239- 1242

- Morris PD, Malkin CJ, Channer KS, Jones TH (2004). A mathematical comparison of techniques to predict biologically available testosterone in a cohort of 1072 men. Eur J Endocrinol 151: 241- 249

- Nieschlag E, Swerdloff R, Behre HM, Gooren LJ, aufman JM, Legros JJ, Lunenfeld B, Morley JE, Schulman C, Wang C, Weidner W, Wu FC (2005). Investigation, treatment and monitoring of late-onset hypogonadism in males: ISA, ISSAM, and EAU recommendations Int J Androl 28: 125- 127 - Santini SA, Carrozza C, Lulli P, Zuppi C, CarloTonolo G,Musumeci S (2006). Atorvastatin treatment does not affect gonadal and adrenal hormones in type 2 diabetes patients with mild to moderate hypercholesterolemia. J Atheroscler Thromb 10: 160 - 164

- Tremblay RR, Dube JY (1974). Plasma concentrations of free and non-TeBG bound testosterone in women on oral contraceptives. Contraception 10: 599-605

- Vermeulen A, Stoica T, Verdonck L (1971). The apparent free testosterone concentration, an index of androgenicity. J Clin Endocrinol Metab 33: 759- 767. 


\section{ادوية ستاتين و نسبة التستوستيرون فى مرضى السكر من النوع الثانى}

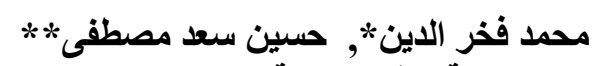

كلية الطب-جامعة المنصورة

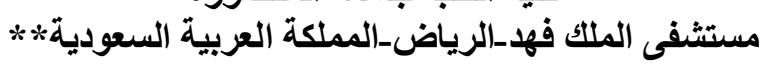

يمكن لادوية ستاتين ان تخفض من نسبة التستوستيرون فى مرضى السكر من النوع الثانى.

و لقد نم البحث على 250 مريض بالسكر تحت العلاج و المتابعة بمستشفى الملك فهد بالرياض_المملكة العربية

السعودية.

و كان جميع المرضى تحت العلاج بادوية الاتورفاستانين و السمفاستاتين.و تم قياس نسبة التستوستيرون فى جميع المرضى.

ووجد ان هناك انخفاض فى نسبة التستوستيرون بمرضى الاتورفاستاتين اكثر من مرضى الهئ السمفاستاتين و يشير

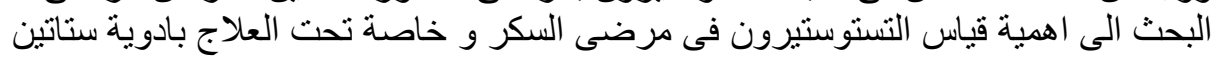

